\title{
Reliability and Validity of Informant-Report Scale on Cognitive-Linguistic Abilities of the Elderly (ISCOLE)
}

\author{
Mi-Sook Lee \\ Graduate School of Special Education, Speech Rehabilitation \& Therapy, Kongju National University, Gongju, Korea
}

Correspondence: Mi-Sook Lee, $\mathrm{PhD}$ Graduate School of Special Education, Speech Rehabilitation \& Therapy, Kongju National University, 56 Gongjudaehak-ro, Gongju 32588, Korea

Tel: $+82-41-850-0846$

Fax: +82-2-8560-5099

E-mail: camusms@hanmail.net

Received: December 29, 2015

Revised: February 10, 2016

Accepted: February 13, 2016

\begin{abstract}
Objectives: Cognitive-linguistic aspects in normal aging decrease the quality of life and may signal symptoms of neurological diseases including mild cognitive impairment and dementia. Therefore, they are increasingly important indicators in an aging society. The aim of this study is to test the reliability and validity of Informant-report Scale on CognitiveLinguistic abilities of the Elderly (ISCOLE). Methods: Data was obtained from elderly adults age 60 or older $(\mathrm{N}=63)$ and their informants $(\mathrm{N}=63)$. Their mean ages were $74.92( \pm 6.02)$ years and 67.65 ( \pm 13.82 ) years, respectively (male:female, 19:44 and 34:29). The type of informants included spouses, children, and others (relatives, friends, caregivers) of the elderly. Reliability and validity was measured on 27 items of ISCOLE. Results: The ISCOLE had the appropriate item internal consistency and test-retest reliability. It also showed highlevel convergent, internal construct, and concurrent validity. Conclusion: The current study indicated that the ISCOLE was reliable and valid as an informant-report scale on cognitivelinguistic abilities of elderly adults. ISCOLE includes various cognitive-linguistic domains including attention, orientation, visuoperception, memory, organization, reasoning, problem solving, executive function, and language. Therefore, ISCOLE can be used for diagnosing a variety of cognitive-linguistic abilities of the elderly. It also contributes to prognostic investigation of performance in each domain.
\end{abstract}

Keywords: Normal aging, Cognitive-linguistic ability, Informant-report scale, Reliability, Validity
인간의 인지-언어 능력은 나이가 들수록 저하된다. 노화로 인해 인지적 자원을 효율적으로 할당하는 능력이나 기억의 용량(capacity) 자체가 변화하기 때문이다(Braver, Satpute, Rush, Racine, \& Barch, 2005; Lee, 2015a). 노년층의 인지-언어적 변화는 일상생활에 서 여러 가지 어려움을 초래한다. 예컨대, 언어능력의 저하로 인해 사회적, 직업적 생활에서 원활한 의사소통이 이루어지지 못한다 (Lee \& Kim, 2012). 또한, 노년기의 가장 보편적인 문제 중 하나인 기억력의 저하는 집행기능, 언어능력 등 다른 기능과 연계되어 전반 적인 삶의 질에 부정적인 영향을 미친다(Lee, 2015a; Vranić, Španić, Carretti, \& Borella, 2013).

노년층의 인지-언어적 변화는 경도인지장애(mild cognitive impairment, $\mathrm{MCI}$ ), 치매 등 신경학적 질환을 예측하는 중요 지표이기 때문에, 인지-언어 능력에 대한 지속적이고 정확한 진단이 요구된
다(Gavett, Dunn, Stoddard, Harty, \& Weintraub, 2011; Lee, 2015b). 노인의 인지-언어 능력에 대한 평가는 다음과 같은 세 가지 측면에 서 활용된다(Woodford \& George, 2007). 첫째, 인지-언어 장애를 선별하는 역할을 한다. 둘째, 인지-언어와 관련된 각종 신경학적 질 환을 진단하기 위한 목적으로 활용된다. 셋째, 질병의 중증도 및 진 전 정도를 예측하는 기능을 한다. 이 같은 목적으로 활용되는 인지언어 능력의 평가 방법으로는 객관적 평가와 주관적 평가를 들 수 있다(Lee, 2015c). 임상가가 대상자에게 직접적으로 실시하는 신경 심리검사, 인지-언어 선별검사, 인지-언어의 하위 영역별 심화검사 등은 '객관적 평가' 방식에 해당한다(Buelow, Tremont, Frakey, Grace, \& Ott, 2014). 반면에, '주관적 평가'는 대상자 본인 또는 보 호자가 인지-언어 능력과 관련된 문항에 응답하는 형태로 구성된 다(Kim, Lee, \& Kim, 2015; Lee, 2015c). 주관적 평가의 두 유형인 자 
기 보고형(self-report)과 정보제공자 보고형(informant-report) 평 가는 객관적 평가와 달리 임상 현장에서 실시할 필요가 없고, 일상 의 기능적인 측면을 반영할 수 있다는 장점이 있다(Buelow et al., 2014; Chung \& Man, 2009). 특히, 최근까지 정보제공자 보고형 평 가의 유용성에 대해 지속적으로 논의되고 있다(Fyocka \& Hampstead, 2015; Jorm, 2004; Slavin et al., 2015). 정보제공자 보고형 주 관적 평가는 일상생활의 인지-언어적 양상이나 장기간의 변화를 관찰자의 시각에서 판단할 수 있어 지속적인 기능성과 객관성을 동시에 확보할 수 있다(Gavett et al., 2011). 또한, 치매환자의 경우 대상자 본인의 감정 상태나 인지-언어적 수준에 따른 영향이 크기 때문에 정보제공자 보고형 평가 방식이 더욱 유용할 수 있다(Clare, Marková, Roth, \& Morris, 2011; Clément, Belleville, \& Gauthier, 2008).

정보제공자 보고형 평가는 주로 노년기에 저하되는 인지-언어의 하위 영역들로 구성된다. 즉, 기초적인 인지 영역으로서 주의력, 지 남력, 기억력 등이 포함되고, 여러 능력들이 연계되어 기능하는 조 직화능력, 추론력, 문제해결력, 집행기능, 언어능력 등의 복합적 영 역이 반영되기도 한다(Jorm, 2004; Malek-Ahmadi, Davis, Belden, Jacobson, \& Sabbagh, 2012). 예를 들어, Multifactorial Memory Questionnaire (MMQ), Prospective and Retrospective Memory Questionnaire (PRMQ) 등은 기억력을 중점적으로 다루고, Dysexecutive Questionnaire (DQ)는 집행기능을 평가하는데 초점을 맞춘 도구이다(Lee, 2015c). 반면에, Informant Questionnaire on Cognitive Decline in the Elderly (IQCODE), 8-item Interview to Differentiate Aging and Dementia (AD8), Cognitive Difficulties Scale (CDS) 등은 인지-언어의 몇몇 하위 영역들로 구성된다(Lee, 2015c). 기존의 도구들은 대부분 노년기에 저하될 수 있는 인지-언 어의 하위 영역들을 광범위하게 포괄하고 있지 않으며, 각 영역별 로 세분화된 범주나 문항을 제시하지 않는 경우가 많다.

국내의 경우 정보제공자 보고형 평가도구가 국외에 비해 다양화 되어 있지 않고, 임상가 평가 방식이나 객관적 평가에 비해 활용도 가 매우 제한적이다(Jeon, Yun, \& Kim, 2010). 국내에서 활용되고 있는 정보제공자 보고형 척도로는 IQCODE-K (Korean version), Korean Dementia Screening Questionnaire (KDSQ), Samsung Dementia Questionnaire (SDQ) 등이 있다. 그러나, 이들 역시 전반 적인 하위 영역들을 포괄하고 있지 않아 노년기에 나타나는 인지언어적 변화를 다양하게 살펴보는 데에 한계가 있다. 예컨대, IQ$\mathrm{CODE}-\mathrm{K}$ 는 기억력, 언어 및 비언어 지능을 중심으로 구성되어 있 고, $\mathrm{KDSQ}$ 의 경우에도 기억력, 언어능력, 행동 및 기능적 능력 등 인 지-언어의 일부 하위 영역에 국한되어 있다.
이처럼, 정보제공자 보고형이 도구에 따라 제한적이고 상이한 영 역을 포함하기 때문에 신뢰도나 타당도를 검증하는 것이 매우 중요 하다. IQCODE와 같은 도구는 이미 다수의 국가에서 신뢰도 및 타 당도가 입증된 바 있다(Jorm, 2004). 반면에, 국내의 경우 광범위한 노년층을 대상으로 한 신뢰도나 타당도를 통한 유용성의 검증이 아 직까지 미흡한 실정이다. 예를 들어, KDSQ는 인지-언어 능력의 경 미한 저하 시에만 유용하며, 집행기능과 같은 영역을 평가하기 어렵 다고 보고된 바 있다(Jeon et al., 2010). SDQ는 설문 시간이 상대적 으로 길어 임상적 활용도가 저하될 수 있다(Shin, 2010). 또한, 기억 력 중심의 항목들로 구성되어 있고, 읽기 및 쓰기에 관한 문항이 있 어 문맹의 노인에게 적용하는 데 한계가 있다(Shin, 2010). 노년층 대상의 인지-언어 능력 평가도구에 대한 신뢰도나 타당도는 다양한 방법으로 검증될 수 있다. 신경병리학적 환자군과 정상 노년층에 모 두 적용할 수 있는 도구들의 경우 주로 두 집단 간 비교를 통해 정상 규준이나 민감도, 특이도 등을 제시한다(Shin, 2010). 기존 도구와 의 상관성을 분석함으로써 타당도를 검증하는 경우도 많은데, 주로 $\mathrm{MMSE}$ 등의 신경심리 평가도구가 활용된다. 예컨대, IQCODE는 MMSE 등과의 전반적인 상관성뿐 아니라 하위 영역별로 여러 신경 심리 평가도구와의 비교를 통해 타당도를 다각적으로 검증한 바 있 다(Li, Jia, \& Jia, 2012; Ozel-Kizil, Turan, Yilmaz, Cangoz, \& Uluc, 2010). 하위 영역들 중에서는 기억력과의 상관성을 규명한 연구들 이 많다(Clarnette, Almeida, Forstl, Paton, \& Martins, 2001; Edmonds, Delano-Wood, Galasko, Salmon, \& Bondi, 2014; Slavin et al., 2015).

요컨대, 노년층의 인지-언어 능력을 평가하기 위한 정보제공자 보고형 척도를 개발하고, 신뢰도 및 타당도를 체계적으로 검증할 필요성은 다음과 같다. 첫째, 정보제공자 보고형 평가는 일상생활 의 수행력을 반영하므로 노인의 인지-언어 능력을 기능적인 측면에 서 살펴보는 데 용이하다. 둘째, 정보제공자 보고형 평가를 통해 노 인의 인지-언어적 양상을 장기적이고 연속적으로 파악할 수 있다. 셋째, 정보제공자가 관찰자의 시각에서 판단하기 때문에 대상자 본 인의 감정이나 수행력의 영향을 배제할 수 있어 노년기의 객관적인 인지-언어 능력을 살펴볼 수 있다. 넷째, 자기 보고형에 비해 평가의 시행에 대한 접근이 용이하다. 다섯째, 개발된 도구의 신뢰도 및 타 당도를 검증함으로써 임상적 활용도를 더욱 높일 수 있다. 이에, 본 연구에서는 '노년기 인지-언어 능력에 대한 정보제공자 보고형 평 가척도(Informant-report Scale on Cognitive-Linguistic abilities of the Elderly, ISCOLE)'를 개발하기 위한 사전 연구로서 본 도구의 신 뢰도 및 타당도를 검증하고자 한다. 신뢰도를 입증하기 위해 내적 일관성 신뢰도와 검사-재검사 신뢰도를 알아보고, 총점 및 하위 영 
역별 타당도는 수렴타당도, 내적구성 타당도, 공인타당도를 통해 분석할 것이다.

\section{연구 방법}

\section{연구 대상}

본 연구의 대상자는 서울 및 경기 지역에 거주하는 만 65세 이상 의 정상 노년층 63 명과 이들의 정보제공자 63 명이었다. 이들은 서울 시 성북구 소재 노인복지관 1 곳, 서울 및 경기 지역 노인정 3 곳으로 부터 표집된 노인과 정보제공자였으며, 기타 개별적인 자원자도 포 함되었다. 노인 집단에 포함되어 연구 절차를 진행하였으나 해당 정 보제공자가 참여하지 않은 14 명은 최종 대상군에서 제외되었다. 본 연구에서 노인 및 정보제공자 집단의 제외 기준으로는 (1) 신경학 적 질환의 병력이 있는 경우, (2) Korean version of Mini-Mental State Examination (K-MMSE; Kang, 2006)상 정상군 규준에서 1 $\mathrm{SD}$ 미만의 수행력을 보이는 경우였다. 정보제공자 중 45 세 미만에 해당하는 9명은 K-MMSE에 정상 규준이 제시되어 있지 않아 MMSE 의 규준(Crum, Anthony, Bassett, \& Folstein, 1993)에 따라 1 SD 미 만의 수행력을 기준으로 하였다.

정상 노년층의 평균 연령 $( \pm$ 표준편차)은 $74.92( \pm 6.02)$ 세였으 며, 이 중 65-74세는 30명, 75세 이상은 33명이었다(남:여, 19:44). 교 육연수의 평균( \pm 표준편차)은 9.94 ( \pm 2.95 년으로, 6년 9명, 6-9년 29 명, 10 년 이상 25 명이었다. 노인 집단을 대상으로 실시한 K$\mathrm{MMSE}$ 의 평균( \pm 표준편차)은 24.83 ( \pm 2.03 )점이었다.

정보제공자는 사전 면담을 통해 대상군의 인지-언어 능력을 잘 파악하고 있는 자들로 선별하였다(Jorm, 2004). 사전 면담의 주요 내용은 다음과 같다. 첫째, 대상 노인과 동거하고 있는 가족 또는 보호자의 유무, 둘째, 대상 노인과 주 1 회 이상 빈번하게 교류하는 가족 또는 보호자의 유무, 셋째, 동거 또는 교류하는 자들 중 정보 제공자 보고형 평가가 가능한지 여부 등이었다. 이를 통해 선별된 정보제공자로는 가족 및 친척, 지인, 기타 보호자 등이었다. 정보제 공자의 평균 연령 $( \pm$ 표준편차)은 67.65 ( \pm 13.82$)$ 세였으며, 남녀 성 비는 34:29였다. 정보제공자 집단에게 실시한 K-MMSE의 평균( \pm

Table 1. Characteristics of participants \& informants

\begin{tabular}{lcc}
\hline Characteristic & Participants & Informants \\
\hline Age (yr) & $74.92(6.02)$ & $67.65(13.82)$ \\
Education level (yr) & $9.94(2.95)$ & $10.59(3.83)$ \\
Gender (male:female) & $19: 44$ & $34: 29$ \\
K-MMSE & $24.83(2.03)$ & $27.67(2.15)$ \\
\hline
\end{tabular}

Values are presented as mean (SD) or number.

K-MMSE = Korean version of Mini-Mental State Examination (Kang, 2006).
표준편차)은 27.67 ( \pm 2.15$)$ 점이었다. 정보제공자의 주요 유형으로 는 배우자가 40 명으로 가장 많았으며, 자녀 14 명, 기타(친척, 지인, 기타 보호자) 9 명 순이었다. 기타 보호자에는 이웃, 가족이 아닌 동 거인이 포함되었다.

연구 대상자의 주요 특성은 Tables 1과 2에 제시하였다.

\section{연구 도구}

노년층의 인지-언어 능력을 평가하는 정보제공자 보고형 도구로 서 개발된 ISCOLE은 주의력(지속 및 분리 주의력), 지남력(사람, 시 간, 장소), 시지각력(시공간력, 시각구성력), 기억력(장기, 단기, 즉각 기억 및 학습능력), 조직화 능력(범주화, 순서화), 추론력(귀납적 및 수렴적 사고), 문제해결력(문제 추론, 의사 결정), 집행기능(계획화, 실행화), 언어능력(이해, 표현, 이름대기, 읽기, 쓰기, 계산, 화용)을 평가하도록 구성되었다. 이전 연구를 통해 ISCOLE의 개발을 위한 관련 문헌 검토 및 내용타당도의 검증이 시행되었으며, 이를 토대 로 예비 문항에 대한 수정 작업을 거쳤다(Lee, 2015c). 또한, 65-74 세 정상 노인의 정보제공자 5 명을 대상으로 예비 조사를 실시한 후 내용의 난이도, 어휘의 친숙도, 문항과 관련된 예시 등을 고려하여 총 7개 문항을 재수정하였다. 최종적으로 ISCOLE은 주의력, 시지 각력, 조직화 능력, 추론력, 문제해결력, 집행기능 각각 2 개, 지남력 3 개, 기억력 4 개, 언어능력 8 개 등 9 개 하위 영역에 해당하는 총 27 개 문항으로 구성되었다(Appendix 1).

정보제공자는 대상 노인의 인지-언어 능력에 대한 질문에 ‘아니 다(0), 약간 그렇다(1), 많이 그렇다(2), 매우 많이 그렇다(3), 항상 그 렇다(4)'의 5 점 척도 중 하나로 평정하도록 하였다. 1 년 전과 비교한 현재의 능력에 대해 평가하며, 점수 분포는 0-108로 점수가 높을수 록 인지-언어적 수행력이 떨어지는 것으로 간주하였다.

이밖에, 노인 집단의 선별 및 수렴타당도의 검증을 위해 KMMSE (Kang, 2006)를 시행하였다. K-MMSE는 지남력(시간, 장 소) 10 개, 기억력(등록, 회상) 6 개, 주의력 및 계산 5 개, 시공간력(그 리기) 1 개, 언어능력 8 개 등 총 30 개 문항으로 구성되어 노인을 포함 한 다양한 대상군에게 적용 가능한 대표적인 선별검사 중 하나이 다. 또한, ISCOLE의 공인타당도를 검증할 목적으로 정보제공자 집

Table 2. Characteristics by type of informant

\begin{tabular}{lccc}
\hline Characteristic & Spouse $(\mathrm{N}=40)$ & Child $(\mathrm{N}=14)$ & Others $(\mathrm{N}=9)$ \\
\hline Age (yr) & $73.65(5.54)$ & $43.79(3.72)$ & $78.11(2.89)$ \\
Education level (yr) & $8.75(2.35)$ & $16.21(1.37)$ & $10.00(3.28)$ \\
K-MMSE & $27.20(2.05)$ & $29.93(.27)$ & $26.22(1.64)$ \\
\hline
\end{tabular}

Values are presented as mean (SD).

K-MMSE = Korean version of Mini-Mental State Examination (Kang, 2006). 
Table 3. Differences of demographic characteristics in elderly group

\begin{tabular}{|c|c|c|c|c|c|c|}
\hline \multirow{2}{*}{ Group } & \multicolumn{2}{|c|}{ Age (yr) } & \multicolumn{2}{|c|}{ Education level (yr) } & \multicolumn{2}{|c|}{ K-MMSE } \\
\hline & M (SD) & $p$-value & $\mathrm{M}(\mathrm{SD})$ & $p$-value & $\mathrm{M}(\mathrm{SD})$ & $p$-value \\
\hline Male $(\mathrm{N}=19)$ & $76.26(6.11)$ & .907 & $10.32(2.33)$ & .136 & $24.79(1.69)$ & .286 \\
\hline Female $(\mathrm{N}=44)$ & 74.34 (5.95) & & $9.77(3.19)$ & & 24.84 (2.18) & \\
\hline
\end{tabular}

K-MMSE = Korean version of Mini-Mental State Examination (Kang, 2006).

Table 4. Differences in type of informant

\begin{tabular}{lcccccc}
\hline \multirow{2}{*}{ Group } & \multicolumn{9}{c}{ Type of informant } & \multirow{2}{*}{$\chi^{2}$} & $F$ & $p$-value \\
\cline { 2 - 5 } & Spouse & Child & Others & & & \\
\hline Male $(\mathrm{N}=19)$ & 13 & 4 & 2 & .390 & 2 & .823 \\
Female $(\mathrm{N}=44)$ & 27 & 10 & 7 & & & \\
Total & 40 & 14 & 9 & & & \\
\hline
\end{tabular}

단에게 Korean Dementia Screening Questionnaire-Cognition (KDSQ-C; Yang, Jo, Choi, Kim, \& Kim, 2002)을 추가로 시행하였 다. KDSQ-C는 기억력, 언어능력, 복잡한 과제 수행능력 등 3개 영 역을 포함하며, 영역별로 5 개씩 총 15 개 문항으로 구성되어 있다. 1 년 전과 비교한 현재의 능력에 대해 정보제공자가 '그렇지 않다(0)약간 그렇다(1)-자주 그렇다(2)'의 3점 척도로 평정한다. 이 도구는 기존에 신뢰도 및 타당도가 검증되어 있는 도구로, 치매의 조기 발 견을 위해 일반 건강검진에서도 활용되고 있다(Jeon et al., 2010).

\section{연구 절차}

2015년 7월부터 12월까지 노인 및 정보제공자 집단을 대상으로 연구 절차를 적용하였다. 먼저, 정상 노년층을 대상으로 사전 면담 을 실시하여 정보제공자의 참여가 가능한지 여부를 파악하였다. 이후 K-MMSE를 통해 최종적으로 노인 집단을 선별하였다.

정보제공자 집단을 대상으로 한 ISCOLE과 KDSQ-C의 적용은 크게 두 가지 유형으로 진행되었다. 첫째, 정보제공자가 해당 노인 과 동반하여 특정 장소에서 평가를 동시에 진행하였다. 둘째, 연구 자가 직접 정보제공자의 가정을 방문하여 진행하였다. 정보제공자 집단에게 시행한 ISCOLE과 KDSQ-C의 총 소요시간은 평균 20-30분이었다.

이밖에, 시간의 경과에 따른 검사-재검사 신뢰도를 알아보기 위 해 정보제공자 집단의 $10 \%$ 에 해당하는 7 명을 대상으로 1 회의 검 사를 추가로 실시하였다. 6 명은 1 차 검사일로부터 14 일 후에 재평 가를 진행하였고, 나머지 1 명은 피검자의 개인 사정에 의해 13 일 후 에 실시하였다.
Table 5. Internal consistency reliability of ISCOLE (Cronbach $\alpha=.642$ )

\begin{tabular}{lcc}
\hline Domain & CITI & Cronbach a if item deleted \\
\hline Attention & .542 & .544 \\
Orientation & .000 & .652 \\
Visuoperception & .112 & .648 \\
Memory & .638 & .504 \\
Organization & .042 & .653 \\
Reasoning & .185 & .643 \\
Problem solving & .113 & .648 \\
Executive function & .397 & .595 \\
Language & .556 & .539 \\
\hline
\end{tabular}

ISCOLE=Informant-report Scale on Cognitive-Linguistic abilities of the Elderly; $\mathrm{CITI}=$ corrected item-total correlation.

\section{통계 분석}

통계 분석을 위해 SPSS ver. 20.0을 활용하였다. 집단별 인구통계 학적 차이를 알아보기 위해 독립표본 $t$-검정(t-test) 및 카이제곱 검 정 $\left(\chi^{2}\right.$-test $)$ 을 시행하였다. 내적일관성 신뢰도 분석을 통해 Cronbach $\alpha$ 값을 살펴보았고, 피어슨 상관계수(Pearson correlation coefficient) 분석에 의해 검사-재검사 신뢰도, 수렴타당도, 내적구성 타당도, 공인타당도를 검증하였다.

\section{연구 결과}

\section{연구 대상의 인구통계학적 차이}

본 연구 대상인 노인 집단 내에서 나타나는 통계적 차이를 분석 한 결과는 Tables 3 과 4 에 제시하였다. 연령 $(t=1.167, p=.907)$, 교육 수준 $(t=.667, p=.136), \mathrm{K}-\mathrm{MMSE}$ 점수 $(t=-.092, p=.286)$ 에 있어 남 녀 간의 유의미한 차이는 나타나지 않았다. 또한, 노인 집단 내에서 정보제공자의 유형에 따른 통계적 차이가 없는 것으로 분석되었다 $\left(\chi^{2}=.390, p=823\right)$.

\section{신뢰도}

내적일관성 신뢰도

ISCOLE의 내적일관성 신뢰도를 분석한 결과, Cronbach $\alpha$ 계수 는 .642로 적절한 수준의 신뢰도를 갖는 것으로 나타났다. 이는 
Table 6. Convergent validity of ISCOLE

\begin{tabular}{ccccccc}
\hline & \multicolumn{5}{c}{ Domains in ISCOLE and K-MMSE } \\
\cline { 2 - 7 } & Attention & Orientation & Visuoperception & Memory & Language & Total \\
\hline$r$ & $-.827^{* *}$ & .033 & .047 & $-.677^{* *}$ & $-.698^{* *}$ & $-.705^{* *}$ \\
\hline
\end{tabular}

ISCOLE= Informant-report Scale on Cognitive-Linguistic abilities of the Elderly; K-MMSE=Korean version of Mini-Mental State Examination (Kang, 2006). ${ }^{* *} p<.01$.

Table 7. Correlation between total score and each domain of ISCOLE

\begin{tabular}{cccccccccc}
\hline & 1 & 2 & 3 & 4 & 5 & 6 & 7 & 8 & 9 \\
\hline Total score & $.558^{* *}$ & $.358^{* *}$ & $.371^{* *}$ & $.595^{* *}$ & $.474^{* *}$ & $.437^{* *}$ & $.342^{* *}$ & $.497^{* *}$ & $.684^{* *}$ \\
\hline
\end{tabular}

ISCOLE=Informant-report Scale on Cognitive-Linguistic abilities of the Elderly; $1=$ attention; 2 = orientation; $3=$ visuoperception; $4=$ memory; $5=$ organization; $6=$ reasoning; $7=$ problem solving; $8=$ executive function; $9=$ language.

${ }^{* *} p<.01$.

Table 8. Concurrent validity of ISCOLE

\begin{tabular}{lccc}
\hline \multirow{2}{*}{ ISCOLE } & \multicolumn{3}{c}{ KDSQ-C } \\
\cline { 2 - 4 } & Memory & Language & Total \\
\hline Memory & $.705^{* *}$ & & \\
Language & & $.672^{* *}$ & $.701^{* *}$ \\
Total & & & \\
\hline
\end{tabular}

ISCOLE = Informant-report Scale on Cognitive-Linguistic abilities of the Elderly; KDSQ-C=Korean Dementia Screening Questionnaire-Cognition (Yang, Jo, Choi, Kim, \& Kim, 2002).

${ }^{* *} p<.01$.

Nunnally와 Bernstein (1994)이 제시한 기준인 .50보다 높고, 일반 적인 연구에서 적절하고 무난한 수준의 신뢰도로 간주되는 .60보 다 높은 수치에 해당한다(Ebel \& Frisble, 1991: Mansfield, 1994). 제 거 시 신뢰도 계수를 향상시키는 데 가장 크게 기여하는 영역은 조 직화능력과 지남력이었다(Table 5).

\section{검사-재검사 신뢰도}

ISCOLE의 검사-재검사 신뢰도를 살펴본 결과, $r=.867(p<.05)$ 로 정보제공자 집단의 응답이 시간의 변화에 따라 일관성 있게 나 타나는 것으로 분석되었다.

\section{타당도}

수렴타당도

수렴타당도를 알아보기 위해 노인 집단의 K-MMSE 점수와 ISCOLE 간의 상관성을 총점 및 하위 영역별로 분석하였다(Table 6). 그 결과, 두 점수의 총점 간에는 유의한 부적 상관성이 있는 것으로 나타났다 $(r=-.705, p<.01)$. 즉, 수행력이 낮을수록 점수가 높게 나 타나는 ISCOLE과, 수행력이 높을수록 점수가 높게 평가되는 KMMSE의 총점 간에는 '높은' 수준의 상관관계가 있음을 알 수 있
었다. 하위 영역 중에는 주의력이 '매우 높은' 수준의 부적 상관성 을 보였다 $(r=-.827, p<.01)$. 기억력 $(r=-.677, p<.01)$ 과 언어능력 $(r=-.698, p<.01)$ 은 두 도구 간에 '높은 상관성이 있었다. 반면에, 지남력과 시지각력은 유의한 상관관계가 나타나지 않았다.

내적구성 타당도

ISCOLE의 총점과 각 하위 영역별 점수 간의 상관성을 분석함으 로써 내적구성 타당도를 살펴보았다(Table 7). 그 결과, 총점은 모든 9 개 영역과 유의미한 상관성을 보였다 $(p<.01)$. 특히, 언어능력은 $r=.60$ 이상으로 총점과 '높은' 상관성이 있었고, 주의력, 기억력, 조 직화 능력, 추론력, 집행기능은 $r=.40$ 이상으로 '다소 높은' 수준의 상관관계를 갖는 것으로 나타났다. 반면에, 지남력, 시지각력, 문제 해결력은 상대적으로 낮은 상관성을 보였다.

\section{공인타당도}

ISCOLE의 공인타당도를 검증하기 위해 KDSQ-C의 총점 및 2 개 하위 영역과의 상관성을 알아보았다. 그 결과, 총점 $(r=.701$, $p<.01)$, 기억력 $(r=.705, p<.01)$, 언어능력 $(r=.672, p<.01)$ 에서 모 두 '높은' 수준의 상관성을 보였다(Table 8).

\section{논의 및 결론}

노년층의 인지-언어적 변화는 전반적인 삶의 질에 큰 영향을 미 친다. 따라서, 노인의 인지-언어 능력을 지속적이고 객관적으로 파 악하는 것이 매우 중요하다(Lee, 2015c; Lee \& Kim, 2012; Mitchell, Beaumont, Ferguson, Yadegarfar, \& Stubbs, 2014). 정보제공자 보 고형 평가는 일관성과 객관성이 확보될 뿐 아니라 기능적 양상을 반영할 수 있어 임상적 활용도를 높일 수 있다(Buelow et al., 2014; 
Chung \& Man, 2009; Clare et al., 2011; Clément et al., 2008; Gavett et al., 2011). 그럼에도 불구하고, 국내에서는 노년층의 인지-언어 능 력에 대한 정보제공자 보고형 평가도구가 양적으로 매우 부족한 실정이다. 또한, 몇몇 도구들의 경우에도 제한적 평가 영역, 유용성 에 대한 검증의 부족, 평가 시행상의 어려움 등으로 인해 임상적 활 용도가 낮은 편이다.

ISCOLE은 노인의 인지-언어 능력을 지속적이고 객관적으로 진 단함과 동시에, 광범위한 하위 영역을 평가할 수 있는 척도의 필요 성에 따라 개발되었다. 본 도구는 10-15분의 짧은 시간 내에 총 27 개 문항에 응답함으로써 주의력, 지남력, 시지각력, 기억력, 조직화 능력, 추론력, 문제해결력, 집행기능, 언어능력 등 9개 하위 영역을 고루 평가할 수 있도록 하였다. 인지-언어 능력은 각 영역 간 연계성 이 강하나, 하위 영역별 수행력을 세부적으로 파악함으로써 신경 병리학적 질환의 예방적 조치를 취하는 데 유용하게 활용될 수 있 다(Lee, 2015a; Lee \& Kim, 2012). ISCOLE의 문항 수를 살펴보면, 기억력 4 개, 나머지 7 개 인지 영역 2-3개, 언어능력 8개로 구성되었 다. 이는 정보제공자 보고형이 정상 노년층의 기억력과 언어능력을 가장 효과적으로 반영한다는 여러 선행 연구 결과에 근거하였다 (Clarnette et al., 2001; Edmonds et al., 2014; Gavett et al., 2011; Lee, 2015b; Slavin et al., 2015). 특히, 노년층을 대상으로 한 기존의 도구 들이 언어능력을 세분화해 구성하지 않은 점을 고려하여 이해 및 표현, 이름대기, 읽기 및 쓰기, 계산, 화용언어 관련 문항을 포함하 였다(Lee, 2015c). 기존의 국내 도구들은 인지-언어의 일부 영역에 한정된 경우가 대부분이다. 예컨대, IQCODE-K는 기억력, 언어 및 비언어 지능 관련 능력을 평가하며, $\mathrm{KDSQ}$ 는 기억력, 언어능력, 행 동 및 기능적 능력에 국한되어 있다. 또한, $\mathrm{SDQ}$ 는 기억력, 언어능력 에 해당하는 문항들이 주를 이룬다. 즉, ISCOLE은 선별검사로서 의 성격을 띠고 있으나, 주관적 평가도구임을 감안하여 일상생활의 다양한 능력을 반영할 수 있는 도구이다. 이는 몇몇 특정 영역만을 다루고 있어 노년기의 인지-언어 능력을 전반적으로 진단하는 데 한계가 있는 기존 도구들을 감안할 때 크게 주목할 만하다. 특히, ISCOLE은 9개 하위 영역을 비교적 짧은 시간 내에 평가할 수 있기 때문에 임상적 활용도를 높일 수 있다는 장점이 있다.

본 연구에서는 개발 중인 문항들에 대한 신뢰도 및 타당도를 구 축함으로써 ISCOLE이 일관성 있고 적절한 정보제공자 보고형 평 가도구임을 객관적으로 입증하고자 하였다. 신뢰도를 검증한 결과, ISCOLE은 적절한 수준의 내적일관성 신뢰도를 갖는 도구임을 알 수 있었다. 일반적으로 신뢰도 계수는 평가도구의 문항 수에 따라 상대적으로 해석된다(Ebel \& Frisble, 1991). 예를 들어, 문항 수가 $10,20,40$ 개로 증가할수록 신뢰도 계수의 적정 수준은 $.33, .50, .67$
로 높아진다. 문항 수가 640개이면 신뢰도 계수가 .97로 매우 높은 수준에 이른다. 따라서, ISCOLE이 27개 문항 수인 점을 감안할 때 본 도구의 신뢰도 계수(Cronbach $\alpha=.642)$ 는 매우 적절한 수준임 을 알 수 있다. 또한, 검사-재검사 신뢰도 역시 높게 나타나 본 도구 가 시간의 변화에 따라 일관성을 갖는 도구임을 입증하였다. 정보 제공자 보고형 평가도구에 대한 신뢰도의 검증은 효과성에 대한 연구와 더불어 다양하게 시도되고 있다(Li et al., 2012; Lourenço \& dos Santos Sanchez, 2014; Ozel-Kizil et al., 2010). 특히, 전 세계적 으로 가장 널리 활용되고 있는 IQCODE는 다수의 국가에서 신뢰 도가 입증된 바 있다(Jorm, 2004). 예를 들어, IQCODE-T (Turkish ver.)의 내적일관성 신뢰도는 매우 높은 수준이나, 검사-재검사 신 뢰도는 상대적으로 낮은 편이다(Ozel-Kizil et al., 2010). IQCODE$\mathrm{K}$ 는 언어능력에 비해 기억력 및 복잡한 과제 수행능력에 대한 신뢰 도가 높게 나타났다(Yang et al., 2002). 대상군에 따른 차이를 살펴 본 연구에 따르면 IQCODE는 $\mathrm{MCI}$ 환자군에게 가장 신뢰도가 높 은 도구이다(Li et al., 2012).

본 연구를 통해 타당도를 분석한 결과는 다음과 같다. 첫째, 노인 집단의 K-MMSE와 ISCOLE의 총점 및 5 개 하위 영역 간의 상관성 을 통해 수렴타당도를 알아보았는데, 두 도구의 총점과 3 개 하위 영 역(주의력, 기억력, 언어능력) 간에 유의한 부적 상관성이 나타났다. 지남력과 시지각력은 상관성이 유의하지 않은 것으로 분석되었다. Lourenço와 dos Santos Sanchez (2014)는 IQCODE와 MMSE, Cambridge Cognitive Examination Test-Revised (CAMCOG-R; Roth, Huppert, Mountjoy, \& Tym, 1998) 간의 총점을 비교함으로써 수렴 타당도를 입증한 바 있다. IQCODE와 MMSE뿐 아니라 하위 영역 별로 여러 신경심리 평가와의 상관성을 분석함으로써 타당도를 심 층 깊게 살펴본 경우도 있다(Li et al., 2012; Ozel-Kizil et al., 2010). 본 연구에서는 인지-언어의 각 하위 영역들이 갖는 독립성과 연계 성을 고려하여, 타당도가 이미 검증되어 있는 K-MMSE와 총점 및 관련 하위 영역들을 비교 분석하였다. 즉, K-MMSE의 총점뿐 아니 라 5 개 하위 영역인 주의력, 지남력, 시지각력, 기억력, 언어능력과 본 도구 간 상관성을 살펴보았다. 특히, 선행 연구들이 주로 총점과 의 상관성에 주목한 데 반해, ISCOLE은 총점 및 3 개 하위 영역(주 의력, 기억력, 언어능력)에서 각각 유의한 상관성이 있음을 입증하 였다. 상관관계가 유의미하지 않게 나타난 지남력과 시지각력의 경 우, 본 도구와 문항 수에서 상대적으로 큰 차이를 보이는 점과 관련 된다. K-MMSE의 주의력은 본 도구와 문항 수에서 차이가 있으나, 계산능력을 동시에 평가하도록 되어 있다는 점을 고려해야 할 것이 다. 즉, ISCOLE에서 계산능력은 K-MMSE와 상관성이 높은 '언어 능력'에 포함되어 있어 주의력의 상관성 또한 높게 나타난 것으로 
판단된다.

둘째, ISCOLE의 총점과 9 개 하위 간에 모두 유의미한 상관성이 있는 것으로 나타나 본 도구가 내적구성 타당도를 지님을 알 수 있 었다. 특히, ISCOLE의 9개 하위 영역 중 언어능력, 주의력, 기억력, 조직화 능력, 추론력, 집행기능은 총점과의 상관성이 크게 나타나 내적구성 타당도를 높이는 데 기여하였다. 언어능력, 기억력, 주의 력과 총점 간의 높은 상관성은 수렴타당도의 검증 결과와 맥을 같 이한다. 언어능력의 경우 문항 수가 다른 영역에 비해 상대적으로 많다는 점도 영향을 미친 것으로 보인다. 조직화 능력, 추론력, 집행 기능은 다수의 인지능력이 결합되어 발현되는 복합적인 영역에 해 당한다. 나이가 들수록 문제의 추론, 관점의 해석 및 전이, 정보의 계획이나 조작, 활동의 시작 및 완성 등에서 저하된 수행력을 보이 는데, 이는 전반적인 삶의 질에 부정적인 영향을 미친다(Gilhooly et al., 2007; Lee, 2015a). 조직화 능력, 추론력, 집행기능은 이 같은 기능들과 직결되는 영역에 해당한다. 특히, 집행기능은 주의력, 기 억력과 같은 기초적인 인지 능력에 기반하여 복합적으로 나타나기 때문에 일상생활 전반에 크게 관여하는 영역이다(Lee \& Kim, 2012). 또한, 언어능력과 집행기능 간의 상관성도 여러 선행 연구를 통해 보고된 바 있다(Lee, 2015a). 따라서, 본 연구를 통해 타당도가 높게 나타난 영역들은 이 같은 유기적인 맥락에서 설명될 수 있다. 한편, 본 연구에서 내적구성 타당도가 상대적으로 낮게 나타난 지 남력, 시지각력 등은 수렴타당도에서도 상관성이 유의미하지 않은 영역들이라는 점을 감안할 때 이와 동일 맥락으로 해석할 수 있다.

셋째, ISCOLE과 KDSQ-C의 총점 및 2개 하위 영역(기억력, 언어 능력)을 비교한 결과 모두 '높은 수준의 상관성을 보여 ISCOLE의 공인타당도가 입증되었다. 본 연구에서는 기존의 정보제공자 보고 형 평가도구를 활용하여 공인타당도를 검증하였는데, 국내에는 표 준화 도구가 양적으로 매우 부족한 실정이어서 모든 영역을 비교하 는 데 한계가 있다. 본 연구의 분석에 포함된 기억력과 언어능력은 두 도구 간에 높은 상관성을 보였는데, 이는 정보제공자 보고형 평 가의 효과성을 분석한 여러 선행 연구에서도 이미 보고된 바 있다 (Lee, 2015b). 예컨대, 정보제공자 보고형은 정상 노년층의 기억력, 언어능력, 집행기능을 정확히 반영하며(Gavett et al., 2011), 특히 기 억력과의 상관성이 높다(Clarnette et al., 2001; Edmonds et al., 2014; Slavin et al., 2015).

요컨대, 본 연구를 통해 ISCOLE이 정상 노년층의 인지-언어 능 력에 대한 정보제공자 보고형 평가도구로서 높은 신뢰도와 타당도 를 지님을 입증할 수 있었다. 무엇보다, ISCOLE은 기존의 국내외 도구들에 비해 인지-언어의 다양한 영역별로 세분화되었다는 점에 서 매우 주목할 만하다. 특히, 본 도구는 언어능력과 관련하여 이해
및 표현, 이름대기, 읽기 및 쓰기, 계산, 화용언어 등 다양한 범주에 해당하는 문항들을 포함하였다. 이는 기존의 도구들이 기억력이나 기능적 영역의 일부로서 언어능력을 중복적으로 평가하거나 ‘의사 소통의 어려움을 피상적으로 질문하는 경우가 많은 점을 감안할 때 더욱 의미있다고 할 수 있다(Jeon et al., 2010; Jorm, 2004; MalekAhmadi et al., 2012). 따라서, ISCOLE은 노화에 따른 인지-언어 능 력의 변화를 다양한 영역별로 살펴봄으로써 임상적 활용도를 높일 수 있고, 각 하위 영역에 따라 예방적 조치를 취하는 데에 적극 기여 할 수 있는 도구이다.

본 연구의 제한점은 다음과 같다. 첫째, 본 연구에서는 수렴타당 도를 알아보기 위해 K-MMSE와 ISCOLE 간의 상관성을, 그리고 공인타당도를 검증하기 위해 KDSQ-C와의 상관성을 총점 및 하위 영역별로 분석하였다. 그러나, 도구들 간의 하위 영역이 서로 다르 고, 모두 선별검사에 해당하므로 결과가 다소 제한적일 수 있다. 따 라서, 추후 다양한 신경심리 검사 결과와의 비교 연구가 필요할 것 으로 보인다. 이를 통해 K-MMSE와 KDSQ-C에 포함되지 않은 영 역들의 타당도를 추가적으로 검증할 수 있을 것이다. 둘째, 영역별 문항 수가 제한적이어서 각 영역에 대해 충분한 대표성을 지니는 데 한계가 있다. 특히, 언어능력은 상대적으로 많은 문항 수로 구성 되어 있어 내적구성 타당도를 높이는 데 기여했을 가능성이 크다. 셋째, ISCOLE은 정보제공자의 평가에 근거하는 주관적인 척도이 므로, 수렴타당도가 낮은 지남력과 시지각력 등의 영역은 직접적이 고 객관적인 평가를 통해 보완할 필요가 있다. 예컨대, 본 도구에서 시지각력에 해당하는 문항은 K-MMSE의 '오각형 그리기' 과제에 비해 대상자 본인의 수행력을 정확하게 반영하기 어렵다. 넷째, 본 연구는 정보제공자의 유형에 따른 영향을 고려하지 않았다. 예를 들어, 정보제공자가 동거하는 가족인 경우와 주 1 회 이상 교류하는 지인인 경우는 평가의 질적 및 양적 측면에서 차이가 있을 수 있다. 후속 연구를 통해 정보제공자의 유형별로 신뢰도 및 타당도를 분 석할 필요가 있다.

\section{REFERENCES}

Braver, T. S., Satpute, A. B., Rush, B. K., Racine, C. A., \& Barch, D. M. (2005). Context processing and context maintenance in healthy aging and early stage dementia of the Alzheimer's type. Psychology and Aging, 20, 33-46.

Buelow, M. T., Tremont, G., Frakey, L. L., Grace, J., \& Ott, B. R. (2014). Utility of the cognitive difficulties scale and association with objective test performance. American Journal of Alzheimer's Disease and Other Dementias, 29, 755-761. 
Chung, J. C., \& Man, D. W. (2009). Self-appraised, informant-reported, and objective memory and cognitive function in mild cognitive impairment. Dementia and Geriatric Cognitive Disorders, 27, 187-193.

Clare, L., Marková, I. S., Roth, I., \& Morris, R. G. (2011). Awareness in Alzheimer's disease and associated dementias: theoretical framework and clinical implications. Aging \& Mental Health, 15, 936-944.

Clarnette, R. M., Almeida, O. P., Forstl, H., Paton, A., \& Martins, R. N. (2001). Clinical characteristics of individuals with subjective memory loss in Western Australia: results from a cross-sectional survey. International Journal of Geriatric Psychiatry, 16, 168-174.

Clément, F., Belleville, S., \& Gauthier, S. (2008). Cognitive complaint in mild cognitive impairment and Alzheimer's disease. Journal of the International Neuropsychological Society, 14, 222-232.

Crum, R. M., Anthony, J. C., Bassett, S. S., \& Folstein, M. F. (1993). Population-based norms for the Mini-Mental State Examination by age and educational level. JAMA, 269, 2386-2391.

Ebel, R. L., \& Frisbie, D. A. (1991). Essential of educational measurement (4th ed.). Englewood Cliffs, NJ: Prentice-Hall.

Edmonds, E. C., Delano-Wood, L., Galasko, D. R., Salmon, D. P., \& Bondi, M. W. (2014). Subjective cognitive complaints contribute to misdiagnosis of mild cognitive impairment. Journal of the International Neuropsychological Society, 20, 836-847.

Fyock, C. A., \& Hampstead, B. M. (2015). Comparing the relationship between subjective memory complaints, objective memory performance, and medial temporal lobe volumes in patients with mild cognitive impairment. Alzheimer's \& Dementia: Diagnosis, Assessment \& Disease Monitoring, 1, 242-248.

Gavett, R. A., Dunn, J. E., Stoddard, A., Harty, B., \& Weintraub, S. (2011). The Cognitive Change in Women Study (CCW): informant ratings of cognitive change but not self ratings are associated with neuropsychological performance over three years. Alzheimer Disease and Associated Disorders, 25, 305-311.

Gilhooly, M. L., Gilhooly, K. J., Phillips, L. H., Harvey, D., Brady, A., \& Hanlon, P. (2007). Real-world problem solving and quality of life in older people. British Journal of Health Psychology, 12(Pt 4), 587-600.

Jeon, Y. J., Yun, K. E., \& Kim, Y. S. (2010). Validation of KDSQ-P as selecting elderly for KDSQ-C. Korean Journal of Health Promotion, 10, 45-52.

Jorm, A. F. (2004). The informant questionnaire on cognitive decline in the elderly (IQCODE): a review. International Psychogeriatrics, 16, 275-293.

Kang, Y. (2006). A normative study of the Korean-Mini Mental State Exami- nation (K-MMSE) in the elderly. Korean Journal of Psychology: General, $25,1-12$

Kim, B. S., Lee, M. S., \& Kim, H. (2015). Subjective language complaints: are they reflected in objective language test performance? Communication Science and Disorders, 20, 214-221.

Lee, M. S. (2015a). A Longitudinal study on cognitive-pragmatic language in normal aging: demographic and experiential influences. Journal of the Korean Gerontological Society, 35, 797-811.

Lee, M. S. (2015b). Meta-analysis of correlation between subjective and objective cognitive-linguistic tests: focused on normal aging, MCI, and Dementia. Journal of the Korea Academia-Industrial Cooperation Society, 16, 7414-7423.

Lee, M. S. (2015c). A study of the content validity of informant-report scale on cognitive-linguistic abilities for the elderly (ISCOLE). Journal of SpeechLanguage and Hearing Disorders, 24, 275-286.

Lee, M. S., \& Kim, H. (2012). Language assessment for normal aging: study of assessment tools and content validity. Journal of Korean Contents Society, 12, 280-292.

Li, F., Jia, X. F., \& Jia, J. (2012). The informant questionnaire on cognitive decline in the elderly individuals in screening mild cognitive impairment with or without functional impairment. Journal of Geriatric Psychiatry and Neurology, 25, 227-232.

Lourenço, R. A., \& dos Santos Sanchez, M. A. (2014). Accuracy of the Brazilian version of the informant questionnaire on cognitive decline in the elderly at screening for dementia in community-dwelling elderly participants: findings from FIBRA-RJ study. Journal of Geriatric Psychiatry and Neurology, 27, 212-219.

Malek-Ahmadi, M., Davis, K., Belden, C. M., Jacobson, S., \& Sabbagh, M. N. (2012). Informant-reported cognitive symptoms that predict amnestic mild cognitive impairment. BMC Geriatrics, 12, 1-6.

Mansfield, E. (1994). Statistics for business and economics: methods and applications (5th ed.). New York, NY: W. W. Norton \& Company.

Mitchell, A. J., Beaumont, H., Ferguson, D., Yadegarfar, M., \& Stubbs, B. (2014). Risk of dementia and mild cognitive impairment in older people with subjective memory complaints: meta-analysis. Acta Psychiatrica Scandinavica, 130, 439-451.

Nunnally, J. C., \& Bernstein, I. H. (1994). Psychometric theory (3rd ed.). New York, NY: McGraw-Hill.

Ozel-Kizil, E. T., Turan, E. D., Yilmaz, E., Cangoz, B., \& Uluc, S. (2010). Discriminant validity and reliability of the Turkish version of Informant 
Questionnaire on Cognitive Decline in the Elderly (IQCODE-T). Archives of Clinical Neuropsychology, 25, 139-145.

Roth, M., Huppert, F. A., Mountjoy, C. Q., \& Tym, E. (1998). CAMDEX-R: the Cambridge Examination for Mental Disorders of the Elderly-Revised. Cambridge: Cambridge University Press.

Shin, J. H. (2010). Diagnosis of dementia: neuropsychological test. Korean Journal of Family Medicine, 31, 253-266.

Slavin, M. J., Sachdev, P. S., Kochan, N. A., Woolf, C., Crawford, J. D., Giskes, K., ... \& Brodaty, H. (2015). Predicting cognitive, functional, and diagnostic change over 4 years using baseline subjective cognitive complaints in the Sydney Memory and Ageing Study. American Journal of Geriatric Psychiatry, 23, 906-914.

Vranić, A., Španić, A. M., Carretti, B., \& Borella, E. (2013). The efficacy of a multifactorial memory training in older adults living in residential care settings. International Psychogeriatrics, 25, 1885-1897.

Woodford, H. J., \& George, J. (2007). Cognitive assessment in the elderly: a review of clinical methods. QJM, 100, 469-484.

Yang, D. W., Jo, B. R., Choi, J. Y., Kim, S. Y., \& Kim, B. S. (2002). The development and validation of Korean Dementia Screening Questionnaire (KDSQ). Journal of Korean Neurological Association, 20, 135-141. 
Appendix 1. Questionnaire for ISCOLE

\section{노년기 인지-언어 능력에 대한 정보제공자 보고형 평가척도(ISCOLE)}

* 1년 전과 비교하여 현재 상태에 해당하는 곳에 표시해 주십시오.

\begin{tabular}{|c|c|c|c|c|c|c|}
\hline 영역 & 문항 & 아니다 & $\begin{array}{l}\text { 약간 } \\
\text { 그렇다 }\end{array}$ & $\begin{array}{c}\text { 많이 } \\
\text { 그렇다 }\end{array}$ & $\begin{array}{c}\text { 매우 } \\
\text { 많이 } \\
\text { 그렇다 }\end{array}$ & $\begin{array}{l}\text { 항상 } \\
\text { 그렇다 }\end{array}$ \\
\hline \multirow[t]{2}{*}{ 주의력 } & 1. 대화나 일에 잘 집중하지 못합니까? & 0 & 1 & 2 & 3 & 4 \\
\hline & 2. 두 가지 이상의 일을 동시에 하지 못합니까? (예: TV 보며 식사하기) & 0 & 1 & 2 & 3 & 4 \\
\hline \multirow[t]{3}{*}{ 지남력 } & 3. 가족, 친구 등 친숙한 사람의 얼굴을 잘 알아보지 못합니까? & 0 & 1 & 2 & 3 & 4 \\
\hline & 4. 오늘 날짜(월, 일, 요일)를 정확히 알지 못합니까? & 0 & 1 & 2 & 3 & 4 \\
\hline & 5. 자신과 가족, 친구가 사는 동네를 정확히 알지 못합니까? & 0 & 1 & 2 & 3 & 4 \\
\hline \multirow[t]{2}{*}{ 시-지각력 } & 6. 익숙한 장소를 잘 찾아가지 못합니까? & 0 & 1 & 2 & 3 & 4 \\
\hline & 7. 글자 쓰기나 그림 그리기가 정확하지 않습니까? (예: 알아보기 힘든 글씨) & 0 & 1 & 2 & 3 & 4 \\
\hline \multirow[t]{4}{*}{ 기억력 } & 8. 젊었을 때 일어났던 일이나 배웠던 것을 잘 기억하지 못합니까? & 0 & 1 & 2 & 3 & 4 \\
\hline & 9. 최근에 일어났던 일이나 약속을 잘 기억하지 못합니까? & 0 & 1 & 2 & 3 & 4 \\
\hline & 10. 물건을 가지러 갔다가 잊어버리고 그냥 옵니까? & 0 & 1 & 2 & 3 & 4 \\
\hline & 11. 새로운 것을 배우는 것이 어렵습니까? & 0 & 1 & 2 & 3 & 4 \\
\hline \multirow[t]{2}{*}{ 조직화 능력 } & 12. 집안의 물건을 제자리에 잘 정리하지 못합니까? & 0 & 1 & 2 & 3 & 4 \\
\hline & 13. 일상적인 일의 순서를 잘 지키지 못합니까? (예: 청소기 돌린 후 걸레질) & 0 & 1 & 2 & 3 & 4 \\
\hline \multirow[t]{2}{*}{ 추론력 } & 14. 특정 상황의 원인을 잘 파악하지 못합니까? (예: 문을 열어서 춥다) & 0 & 1 & 2 & 3 & 4 \\
\hline & 15. 비슷하거나 반대되는 말을 잘 알아듣지 못합니까? (예: 외출하다-나가다) & 0 & 1 & 2 & 3 & 4 \\
\hline \multirow[t]{2}{*}{ 문제해결력 } & 16. 일상적인 문제에 대해 잘 판단하지 못합니까? & 0 & 1 & 2 & 3 & 4 \\
\hline & $\begin{array}{l}\text { 17. 특정 상황에 대해 두 가지 이상의 방안을 제시하지 못합니까? } \\
\text { (예: 집안에 냄새가 날 때 } \rightarrow \text { 문 열기, 가스불 확인하기) }\end{array}$ & 0 & 1 & 2 & 3 & 4 \\
\hline \multirow[t]{2}{*}{ 집행기능 } & 18. 익숙한 도구나 기계를 다루는 것이 어렵습니까? & 0 & 1 & 2 & 3 & 4 \\
\hline & 19. 상점에서 필요한 물건을 구입하는 것이 어렵습니까? & 0 & 1 & 2 & 3 & 4 \\
\hline \multirow[t]{8}{*}{ 언어능력 } & 20. 대화 도중 같은 질문을 여러 번 반복합니까? & 0 & 1 & 2 & 3 & 4 \\
\hline & 21. 자신의 의견이나 감정을 잘 표현하지 못합니까? & 0 & 1 & 2 & 3 & 4 \\
\hline & 22. 가족, 친구, 물건의 이름을 잘 말하지 못합니까? & 0 & 1 & 2 & 3 & 4 \\
\hline & 23. 책, 신문, 광고 전단지 등을 읽고 내용을 잘 이해하지 못합니까? & 0 & 1 & 2 & 3 & 4 \\
\hline & 24. 가족, 친구 등과 메모나 편지를 주고받는 것이 어렵습니까? & 0 & 1 & 2 & 3 & 4 \\
\hline & 25. 일상에서 계산하는 능력이 떨어집니까? (예: 거스름돈, 물건의 양 계산하기) & 0 & 1 & 2 & 3 & 4 \\
\hline & 26. 비유적인 표현이나 유머를 잘 이해하지 못합니까? (예: 쟁반 같은 달) & 0 & 1 & 2 & 3 & 4 \\
\hline & 27. 두 명 이상의 사람들과 대화하는 것이 어렵습니까? & 0 & 1 & 2 & 3 & 4 \\
\hline
\end{tabular}




\section{국문초록}

\section{노년기 인지-언어 능력에 대한 정보제공자 보고형 평가척도(ISCOLE)의 신뢰도 및 타당도 연구 이미숙}

공주대학교 특수교육대학원 언어재활 전공

배경 및 목적: 노년층의 인지-언어적 변화는 전반적인 삶의 질을 저하시킬 뿐 아니라 신경학적 질환의 전조 증상일 수 있어, 고령화 사회로 갈 수록 중요성이 가중되고 있다. 본 연구에서는 "노년기 인지-언어 능력에 대한 정보제공자 보고형 평가척도(Informant-report Scale on Cognitive-Linguistic abilities for the Elderly, ISCOLE)'의 타당도 및 신뢰도를 검증하고자 한다. 방법: 본 연구는 서울 및 경기 지역의 만 65세 이상 정 상 노년층 및 정보제공자 각 63명을 대상으로 하였다. 노인 및 정보제공자 집단의 평균 연령은 각각 $74.92( \pm 6.02), 67.65( \pm 13.82)$ 세였으며, 남 녀 성비는 19:44, 34:29였다. 정보제공자의 주요 유형은 배우자, 자녀, 기타 순으로 많았다. 결과: ISCOLE은 적절한 수준의 내적일관성 신뢰도 및 검사-재검사 신뢰도를 가지며, 노인 집단의 K-MMSE 점수와 높은 부적 상관성을 보였다. 또한, ISCOLE이 높은 수준의 내적구성 타당도와 공인타당도가 있음을 알 수 있었다. 논의 및 결론: 본 연구를 통해 ISCOLE이 정상 노년층의 인지-언어 능력에 대한 정보제공자 보고형 평가도 구로서 높은 신뢰도와 타당도를 지님을 입증하였다. ISCOLE은 노화에 따른 인지-언어 능력의 변화를 다양한 영역별로 살펴봄으로써 임상적 활용도를 높일 수 있고, 각 하위 영역에 따라 예방적 조치를 취하는 데에 적극 기여할 수 있을 것이다.

핵심어: 노년층, 인지-언어 능력, 정보제공자 보고형 평가척도, 신뢰도, 타당도

\section{참고문헌}

강연욱(2006). K-MMSE (Korean-Mini Mental State Examination)의 노인 규준 연구. 한국심리학회지: 일반, 25, 1-12.

신준현(2010). 치매의 진단: 신경심리검사. 대한가정의학회지, 31, 253-266.

양동원, 조비룡, 최진영, 김상윤, 김범생(2002). Korean Dementia Screening Questionnaire (KDSQ)의 개발과 타당도 및 신뢰도의 평가. 대한신경과 학회지, 20, 135-141.

이미숙(2015a). 노년층의 인지-화용언어 능력에 관한 종단 연구: 영향 요인들을 중심으로. 한국노년학, 35, 797-811.

이미숙(2015b). 메타분석을 통한 주.객관적 인지-언어 평가 간 상관성 연구: 정상 노년층, $\mathrm{MCI}$, 치매 환자를 중심으로. 한국산학기술학회논문지, 16 ,

7414-7423.

이미숙(2015c). 노년기 인지-언어 능력에 대한 정보제공자 보고형 평가척도(ISCOLE)의 내용타당도 연구. 언어치료연구, 24, 275-286.

이미숙, 김향희(2012). 노년층의 인지-화용언어 능력 평가: 평가도구 및 내용타당도 연구. 한국콘텐츠학회논문지, 12, 280-292.

전영지, 윤경은, 김영식(2010). 국민건강보험공단 일반 검진 설문지에 포함된 인지기능 선별문항(KDSQ-P)의 유용성. 대한임상건강증진학회지, 10 , 45-52. 